\title{
Comparative Study Between Mass Closure and Hughes Repair in Emergency Laparotomy
}

\author{
Abd allah Soliman', Ahmed Aly Khalil ${ }^{2}$ and E.F. Ebied ${ }^{2 *}$
}

*Correspondence: dr_essam@hotmail.com

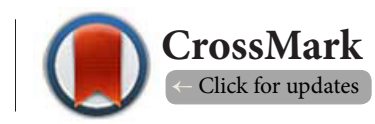

${ }^{1}$ Assistant lecturer of General Surgery Ain Shams university, 36 Iran street, Dokkii, Cairo, Egypt. ${ }^{2}$ Assistant professor of General Surgery Ain Shams University, 36 Iran street, Dokkii, Cairo, Egypt.

\begin{abstract}
Background: Exploratory laparotomy is not an uncommon operation. and safe closure of laparotomy wound is the key to reduce the postoperative morbidity like wound pain, wound infection and incisional hernia.

Objective: To compare mass closure and Hughes repair in emergency laparotomy as regard intra operative technique, operative time, complications as wound infection, dehiscence and incisional hernia. Patients and methods: prospective comparative study between Mass closure and Hughes repair in emergency laparotomy. We include all patients 18 years old or older who underwent emergency laparotomy in Ain Shams University Hospital from September 2017 to March 2018 , we excluded patients with previous hernia and less than 18 years old. All patients were followed up for 6 months.

Results: We recruited 66 patients, (44) patients had mass closure, age range 22-88, 31 (70.5\%) males, $13(29.5 \%)$ females ,(22) patients had Hughes repair, age range $22-89,14(63.6 \%)$ males, $8(36.4 \%)$ females. Operative time in mass closure 15.25-/+ 1.6, in Hughes repair 27.09-/+ 1.66. 6 patients ( 13.6$) \%$ developed incisional hernia after mass closure while 2 patients $(9.1 \%)$ after Hughes repair, in comparison between the mass closure and Hughes repair ,7 patients ( $15.9 \%)$ developed wound infection after mass closure and 3 patients $(13.6 \%)$ after Hughes repair, Burst abdomen in 3 patients $(6.8 \%)$ after mass closure, 1 patient $(4.5 \%)$ after Hughes repair.
\end{abstract}

Conclusion: Hughes repair is associated with less incidence of incisional hernias and wound related complications and could be safely used

Keywords: Incisional hernia, hughes repair, abdominla closure

\section{Introduction}

Incisional hernias are defects which develop around the site of the scar of previous laparotomy and some of them are overt and could be detected clinically and others are radiologically detected [1]. They are a common complication following midline incisions and are associated with increased morbidity and affect the quality of life and hence further repair may increase the economic burden and overall cost [2]. Wound healing is affected by multi factors, some are local factors related to wound itself and the wound closure and a group of factors is systemic related to the medical back ground of the patient and the general state of the patient [3]. The standard way of abdominal closure is mass closure using non absorbable sutures [4], however so far there is no consensus on the best technique or the best suture material to be used .Hughes repair was described by professor Leslie Hughes and also known as Cardiff repair [5], combines a standard mass closure with a series of horizontal and two vertical mattress sutures within a single suture, theoretically distributing the load along the incision length as well as across it [6].

\section{Aim of the Work}

To compare mass closure \& Hughes repair in emergency laparotomy as regard operative time, incidence of complication as 
Ebied et al., Chronicles of Surgery 2021,

wound infection, dehiscence, burst abdomen and incisional hernia.

\section{Subjects and methods \\ Type of study}

This was a prospective comparative study between two types of closure, mass closure and Hughes repair in emergency laparotomies.

\section{Study setting}

This study was conducted at Ain-Shams University Emergency Hospitals. Patients who underwent emergency laparotomy between September 2017 to March 2018 and the patients were followed up postoperatively for six months.

We included patients who were 18 years and older and capable of giving informed consent to understand the procedure and the technique and will undergo mid line laparotomy on emergency basis. While we excluded patients $<18$ years, with previous mesh repair mesh repairs, patients with existing hernia and patients not in sound mind to give consent.

\section{Sampling method}

According to the inclusion and exclusion criteria, Patients were randomly chosen and allocated in two groups who underwent emergency laparotomy at Ain Shams University Hospitals. The study was approved by the Ethics Board of Ain Shams University.

\section{Sample size}

The total number of patients who were included in the study during the study period was 66 patients.

\section{Study design}

\section{Patients were divided in two groups}

Group A: we used the conventional method "Mass closure" in abdominal closure and their number was 44 patients.

Group B: we used the technique of Hughes abdominal repair in abdominal closure and their number was 22 patients.

\section{Study Tools}

\section{Preoperative work up}

- Full clinical assessment.

- Laboratory investigations: $C B C$, Coagulation profile, liver function tests, kidney function tests, Serum electrolytes, viral markers.

\section{Group A: Mass closure technique}

We used PDS loop 1, we started from the upper and lower pole of the wound in a continuous fashion, and Suture was run in 1-cm intervals (maximally), with at least a $1-\mathrm{cm}$ bite of fascia in each throw.

\section{Group B: Hughes repair technique}

It is a series of horizontal and two vertical mattress sutures in the same stitch which lead to tension distribution across the wound.

\section{Post-operative workup}

Patients were checked and examined daily until discharge from the hospital and vital data was collected and recorded. Patients received IV antibiotics and fluids for 5 days postoperative. Wounds were checked for pain, discharge, infection and dehiscence. After discharge, patients were followed up at our outpatient clinic after one week, two weeks, one month, 4 months and six months. At the fourth and the sixth month we checked for the incisional hernia clinically and with anterior abdominal wall ultra sound scan.

\section{Statistical analysis}

Recorded data were analyzed using the statistical package for social sciences, version 20.0 (SPSS Inc., Chicago, Illinois, USA). Quantitative data were expressed as mean \pm standard deviation (SD). Qualitative data were expressed as frequency and percentage. The following tests were done: Independentsamples t-test of significance was used when comparing between two means. Chi-square $\left(x^{2}\right)$ test of significance was used in order to compare proportions between two qualitative parameters. The confidence interval was set to $95 \%$ and the margin of error accepted was set to $5 \%$.

\section{Results}

Tables 1-3.

Table 1. Demographic data of the 2 groups.

\begin{tabular}{llll}
\hline \multirow{2}{*}{ No. $\mathbf{4 4}$} & & Mass closure & Hughes repair \\
\cline { 3 - 4 } & & No. $=\mathbf{2 2}$ & \\
\hline \multirow{2}{*}{ Age (years) } & Mean \pm SD & $48.68 \pm 14.12$ & $52.77 \pm 16.58$ \\
& Range & $22-88$ & $22-89$ \\
\hline \multirow{2}{*}{ Gender } & Female & $13(29.5 \%)$ & $8(36.4 \%)$ \\
& Male & $31(70.5 \%)$ & $14(63.6 \%)$ \\
\hline BMI & Mean \pm SD & $28.25 \pm 4.97$ & $29.55 \pm 3.86$ \\
& Range & $19-43$ & $21-42$ \\
\hline
\end{tabular}

\section{Discussion}

Incisional hernia and surgical site infections are most encountered complications following mid line laparotomy, with incidence $10-15 \%$ and $15-25 \%$ respectively [7].

Despite continuous work to establish guide lines for abdominal wall closure still no consensus on the ideal method for closure of abdominal wall following emergancy laparotomy and future work is needed and encouraged in the future to cover this aspect as most wounds in emergency settings are classified as contaminated and caries an increased risk of herniation and a risk assessment module by Van Rmshorst could be used $[8,9]$.

Hughes repair was named after Professor Hughes who proved that this technique is superior to mesh repair in in- 
Table 2. Comparison between the groups as regarding the operative time.

\begin{tabular}{|c|c|c|c|c|c|c|}
\hline \multirow[t]{2}{*}{ No. $=44$} & & Mass closure & Hughes repair & Test value & P-value & Sig. \\
\hline & & \multicolumn{5}{|l|}{ No. $=22$} \\
\hline \multirow[t]{2}{*}{ Operative time } & Mean \pm SD & $15.25 \pm 1.60$ & $27.09 \pm 1.66$ & -27.983 & 0.000 & HS \\
\hline & Range & $12-19$ & $24-31$ & & & \\
\hline
\end{tabular}

-: Independent t-test; ${ }^{*}$ : Chi-square test

NS: Non significant; S: Significant; HS: Highly significant

P-value $>0.05$ Non significant

P-value $<0.05$ Significant

P-value $<0.01$ highly significant

Table 3. Comparison between mass closure group and huges repair group regarding Incisional hernia formation, wound infection, burst abdomen.

\begin{tabular}{|c|c|c|c|c|c|c|}
\hline No. $=44$ & & $\begin{array}{l}\text { Mass closure } \\
\text { No. }=22\end{array}$ & Hughes repair & Test value & P-value & Sig. \\
\hline \multirow{2}{*}{ Incisional hernia } & No & $38(86.4 \%)$ & $20(90.9 \%)$ & 0.284 & 0.594 & NS \\
\hline & Yes & $6(13.6 \%)$ & $2(9.1 \%)$ & & & \\
\hline \multirow[t]{2}{*}{ Wound infection } & No & $37(84.1 \%)$ & $19(86.4 \%)$ & 0.059 & 0.808 & NS \\
\hline & Yes & $7(15.9 \%)$ & $3(13.6 \%)$ & & & \\
\hline \multirow[t]{2}{*}{ Burst abdomen } & No & $41(93.2 \%)$ & $21(95.5 \%)$ & 0.133 & 0.715 & NS \\
\hline & Yes & $3(6.8 \%)$ & $1(4.5 \%)$ & & & \\
\hline
\end{tabular}

-: Independent t-test; ${ }^{*}$ : Chi-square test

NS: Non significant; S: Significant; HS: Highly significant

P-value $>0.05$ Non significant

P-value $<0.05$ Significant

P-value $<0.01$ Highly significant

cisional hernia and also the same technique was studied by Godara et al and he had the same results [10].

Upon looking through published data the assessment of this technique as method for primary closure in emergency laparotomy is very limited, it was assessed for primary closure by Rajasekaran et al. but he included all patients after emergency and elective laparotomy while in our work we were focused only on closure of emergency laparotomy. $8 \%$ of his patients developed incisional hernia after Hughes closure and $14 \%$ developed incisional hernia after one year following mass closure, while $9 \%$ of our patients developed incisional hernia after Hughes repair and $13.6 \%$ developed incisional hernia after primary closure. Despite the difference in the inclusion criteria the results are almost close which means Hughes repair in general in effective in primary laparotomy closure despite of the indication of the laparotomy [11]. HART trial is one trial studying the technique for closure in patients after elective cancer surgery but the results are not published yet but hopefully this will shed some light on the validity of the technique for closure.

\section{Conclusion}

Hughes repair is associated with less incidence of incisional hernia and wound related complications but however the data available is still limited to conclude that this technique could be the gold standard technique for primary closure in emergency laparotomy, but it is safe and associated with low morbidity and more work to study this technique is advised.

\section{Competing interests}

The authors declare that they have no competing interests.

\section{Authors' contributions}

\begin{tabular}{|l|c|c|c|}
\hline Authors' contributions & AS & AAK & EE \\
\hline Research concept and design & $\sqrt{ }$ & $\sqrt{ }$ & $\sqrt{ }$ \\
\hline Collection and/or assembly of data & $\sqrt{ }$ & $\sqrt{ }$ & $\sqrt{ }$ \\
\hline Data analysis and interpretation & $\sqrt{ }$ & $\sqrt{ }$ & $\sqrt{ }$ \\
\hline Writing the article & $\sqrt{ }$ & $\sqrt{ }$ & $\sqrt{ }$ \\
\hline Critical revision of the article & $\sqrt{ }$ & $\sqrt{ }$ & $\sqrt{ }$ \\
\hline Final approval of article & $\sqrt{ }$ & $\sqrt{ }$ & $\sqrt{ }$ \\
\hline Statistical analysis & $\sqrt{ }$ & $\sqrt{ }$ & $\sqrt{ }$ \\
\hline
\end{tabular}

Publication history

Editor: Sawsan Abuhamdah, University of Jordan, Jordan. Received: 06-Aug-2021 Final Revised: 18-Sept-2021

Accepted: 24-Sept-2021 Published: 13-Oct-2021

\section{References}

1. Korenkov M, Paul A, Sauerland S, et al. Classification and surgical treatment of incisional hernia. Results of an experts' meeting. Langenbecks Arch Surg. 2001;386(1):65-73.) 
Ebied et al., Chronicles of Surgery 2021,

http://www.hoajonline.com/journals/pdf/2053-7212-9-2.pdf

2. Muysoms FE, Miserez $M$, Berrevoet $F$, et al. Classification of primary and incisional abdominal wall hernias. Hernia. 2009;13(4):407-14.

3. Begum B, Zaman R, Ahmad MU et al. (2008): Burst abdomen- a preventable morbidity. Maymunsingh Med J., 17(1): 63-66.

4. Sajid MS, Parampalli U, Baig MK, McFall MR. A systematic review on the effectiveness of slowly-absorbable versus non-absorbable sutures for abdominal fascial closure following laparotomy. Int J Surg. 201.

5. Shukla VK, Gupta A, Singh H, et al. Cardiff repair of incisional hernia: a university hospital experience. Eur J Surg. 1998;164(4):271-4.

6. Hughes repair has proven to be effective as repair with mesh in 9ncisonal hernia Godara R, Garg P, Shankar G. Comparative evaluation of Cardiff repair and mesh plasty in incisional hernias. Internet J Surg [Internet]. 2007.

7. Heger P, Pianka F, Diener MK, Mihaljevic AL. Current standards of abdominal wall closure techniques: conventional suture techniques. The surgeon. J Surg Med. 2016;87(9):737-43.

8. van Ramshorst GH, Nieuwenhuizen J, Hop WC, Arends P, Boom J, Jeekel J, Lange JF (2010) Abdominal wound dehiscence in adults: development and validation of a risk model. World J Surg 34:20-27.

9. Eeuropean hernia society guidelines on the closure of abdominal wall incisions, f. e. muysoms, s. a. antoniou, k. bury, g. campanelli, j. conze, d. cuccurullo, a. c. de beaux, e. B. Deerenberg, B. East, R. H. Fortelny, J.-F. Gillion, N. A. Henriksen, L. Israelsson, A. Jairam, A. Jänes, J. Jeekel, M. López-Cano, M. Miserez, S. Morales-Conde, D. L. Sanders, M. P. Simons, M. Śmietański, L. Venclauskas \& F. Berrevoet Hernia volume 19, pages1-24(2015)).

10. Godara R, Garg P, Shankar G. Comparative evaluation of Cardiff repair and mesh plasties in incisional hernias. Internet J Surg. 2007;9.

11. Rajasekaran C., Vijaykumar K., Arulkumaran M., Meera S. S.A randomized controlled study to compare the efficacy of hughes abdominal repair with conventional abdominal closure-to reduce the incidence of incisional hernias in Indian population.Int Surg J. 2017 Jul;4(7):2291-2293.

\section{Citation:}

Soliman AA, Khalil AA and Ebied EF. Comparative Study Between Mass Closure and Hughes Repair in Emergency Laparotomy. Chron Surg. 2021; 9:2.

http://dx.doi.org/10.7243/2053-7212-9-2 